\title{
The evolutionary appearance of signaling motifs in PGRMC1
}

\author{
Michael A. Cahill* \\ School of Biomedical Sciences, Charles Sturt University, Wagga Wagga, Australia.
}

\begin{abstract}
Summary A complex PGRMC1-centred regulatory system controls multiple cell functions. Although PGRMC1 is phosphorylated at several positions, we do not understand the mechanisms regulating its function. PGRMC1 is the archetypal member of the membrane associated progesterone receptor (MAPR) family. Phylogentic comparison of MAPR proteins suggests that the ancestral metazoan "PGRMC-like" MAPR gene resembled PGRMC1/PGRMC2, containing the equivalents of PGRMC1 Y139 and Y180 SH2 target motifs. It later acquired a CK2 site with phosphoacceptor at S181. Separate PGRMC1 and PGRMC2 genes with this "PGRMC-like" structure diverged after the separation of vertebrates from protochordates. Terrestrial tetrapods possess a novel proline-rich PGRMC1 SH3 target motif centred on P64 which in mammals is augmented by a phosphoacceptor at PGRMC1 S54, and in primates by an additional S57 CK2 site. All of these phosphoacceptors are phosphorylated in vivo. This study suggests that an increasingly sophisticated system of PGRMC1-modulated multicellular functional regulation has characterised animal evolution since Precambrian times.
\end{abstract}

Keywords: Phosphorylation, evolution, steroid signalling, kinases, metazoan

\section{Introduction}

Progesterone Receptor Membrane Component 1 (PGRMC1) is the archetypical protein of the Membrane Associated Progesterone Receptor (MAPR) family, which consists of proteins which share a basic cytochrome $\mathrm{b}_{5}\left(\mathrm{Cytb}_{5}\right)$ domain fold, with the common insertion of a strectch of amino acids between helices 3 and 4 of the domain fold of cytochrome b5 itself (1) (hereafter referred to as the MAPR-specific inter-helical insertion region, or MIHIR). Humans possess four MAPR proteins: PGRMC1, PGRMC2, Neudesin, and Neuferricin (2-4).

PGRMC1 is associated with an uncharacteristically large number of attested functions, including association with cytochrome P450 (CyP450) enzymes (activating steroidogenic CyP450s and repressing xenobiotic metabolizing CyP450s), regulation of sterol synthesis (conversion of lanosterol to cholesterol) and interaction with the INSIG1/SCAP/SREBP complex

Released online in J-STAGE as advance publication February 28, 2017.

*Address correspondence to:

Dr. Michael Cahill, School of Biomedical Sciences, Charles Sturt University, Wagga Wagga, NSW 2678, Australia.

E-mail: mcahill@csu.edu.au that regulates synthesis of sterol precursors, conferring responsiveness to progesterone (pregn-4-ene-3,20dione, hereafter: P4), activating vesicle trafficking, regulating entry into G0 stage of cell cycle, association with Aurora kinase on the mitotic spindle kinetochore, participation in the protein complex containing the Sigma 2 Receptor, angiogenesis, invasive growth, motility, anchorage-independent growth, and hypoxic biology (reviewed by (5)). It is also localized to the outer mitochondrial membrane, where it interacts with Ferrochelatase $(\mathrm{FECH})$, the final enzyme in the heme synthetic pathway (6). The yeast PGRMC1 homolog Dap1 is thought to be involved in either heme synthesis, or its cellular transport to Erg11p, the yeast sterologenic CyP450 enzyme (7). Based upon these observations, PGRMC1 has been proposed to be involved in the transport of heme $(\sigma)$ and perhaps other hydrophobic ligands ( 8 ) between subcellular locations.

The acquisition of multiple functions by PGRMC1 presumably occurred throughout evolution in a successive manner to produce a set of stratified influences. For instance PGRMC1 association with the mitotic spindle could represent a universal eukaryotic MAPR trait, or may represent a metazoan, vertebrate, or mammalian innovation. Sterol or heme synthesis are ancestral traits of all eukaryotes, and are indeed also widespread in bacteria $(9,10)$. The involvement 
of PGRMC1 and its yeast homolog Dap1 in the conversion of lanosterol to cholesterol (animals) or ergosterol (yeast) (11) argues strongly for an ancestral eukaryotic role of MAPR proteins in sterol production, and perhaps also in heme synthesis based upon a role proposed by Ghosh et al. for yeast (7) and by Piel et al. in mammals ( 6 ).

On the other hand the presence of PGRMC1/MAPR proteins in the complex containing INSIG/SCAP/SREBP that regulates the mevalonate pathway leading to sterol precursor synthesis in animals (12) (reviewed in (13)), but not reported in yeast, argues that this should be an acquired higher organism PGRMC1-function. Similarly, steroid hormone signaling first evolved in metazoans. The Estrogen Receptor (ESR), the original classical steroid receptor, appeared in the lineage that gave rise to vertebrates, with subsequent classical steroid receptors such as the P4 receptor evolving later (14-16). Therefore, conferring $\mathrm{P} 4$ responsiveness onto cells is presumably an acquired secondary function (unless a PGRMC1-like P4response predates the estrogen response).

Finally, both mammalian PGRMC1 and its nematode homologue VEM-1 fulfil conserved roles in animal embryogenesis by regulating the fidelity of nerve chord axonal guidance along the ventral midline of nematodes and the spinal chord of rats (17-19). While this function must be ancient in animals, axonal guidance must also be acquired by animals and absent from protists. I have previously proposed that this function relies on the vesicle trafficking properties of PGRMC1 to expose specifc cell surface receptors required axonal guidance (5). If so, then vesicle trafficking may be another acquired metazoan PGRMC1 function.

I have previously proposed that PGRMC1 phosphorylation plays a paramount role in the regulation of its function $(20,21)$. In this paper I have assessed the evolutionary appearance of PGRMC1 phosphorylation sites using BLASTp and CLUSTAL alignments by sampling MAPR proteins in some strategically selected species thought to be phylogentically separated by differing evolutionary periods. This study creates a novel systematics and rationale in this field for the future experimental stratification and functional characterization of PGRMC1 and other MAPR protein functions.

\section{Materials and Methods}

\subsection{Phosphosite post-translational modifications}

The Phosphosite data base of post translational modifications (PTMs) detected by high throughput mass spectrometry analyses (22) was queried with UniProt IDs for human PGRMC1 (O00264), PGRMC2 (O15173), Neudesin (Q9UMX5) and Neferricin (Q8WUJ1). Any PTM scored by Phosphosite with a frequency of once or more was marked on the CLUSTAL multiple sequence alignment of Figure 1A.

\subsection{BLAST and CLUSTAL analysis}

For Figure 1, PGRMC1 (UniProt O00264) used as search sequence in the UniProt Protein Basic Local Alignment Search Tool (BLASTp) (http://www.uniprot.org/blast/). In the results, organisms were deliberately restricted to Homo sapiens, the flowering plant Arabidopsis thaliana, the fusion yeast Schizosaccharomyces pombe, and the budding yeast Saccharomyces cerevisiae. The results (4 human proteins, 4 Arabidopsis proteins, one protein for each yeast species) were aligned by inputting their UniProt IDs to the UniProt CLUSTAL O (1.2.3) (23) multiple sequence alignment tool (UniProt Align) (http:// www.uniprot.org/align/). The CLUSTAL guide tree for Figure 1B was recreated and coloured in Powerpoint to accurate relative scale as the original. For Figure 1C-D, the human Neudesin UniProt ID (Q9UMX5) was used as BLASTp input, and selected phylogentically diverse species were chosen.

For Figure 2 and Table 1, the Uniprot FASTA sequences for the four human MAPR proteins were BLASTed against the indicated individual specific organisms using the NCBI BLASTp page (https:// blast.ncbi.nlm.nih.gov). The FASTA sequences of all identified MAPR proteins were then aligned with the Uniprot FASTA sequences for the four human MAPR proteins using the UniProt CLUSTAL multiple sequence alignment tool, as described above, and designated as Neudesin-like, Neuferricin-like, PGRMC-like, PGRMC1-like or PGRMC2-like by closest alignment to human MAPR proteins in CLUSTAL tree topology.

Subsequent BLAST analyses were performed with NCBI BLASTp with query sequences and Organism taxid ID as described for each study. The top resulting BLASTp results were chosen, and FASTA sequence files added with NCBI identifiers to UniProt Align. The BLAST Query sequences were entered with UniProt Identifiers to color highlight them in UniProt Align results.

\section{Results}

\subsection{Phosphorylation sites are variously conserved among MAPR proteins}

PGRMC1 phosphorylations as documented in the Phosphosite data base (22) have been presented previously (21), as have PGRMC2 sites (8). Figure $\mathrm{S} 1$ shows the complete set of Phosphosite posttranslational modifications (PTMs) documented for all four human MAPR proteins. Figure 1A maps the PTMs from Figure S1 on human MAPR proteins aligned against the sequences of two phylogentically divergent yeast Dap1p MAPR family members, and four MAPR family members from the plant Arabidopsis thaliana. Phosphorylation of a Casein Kinase 2 (CK2) consensus motifs adjacent a C-terminal Src Homology 

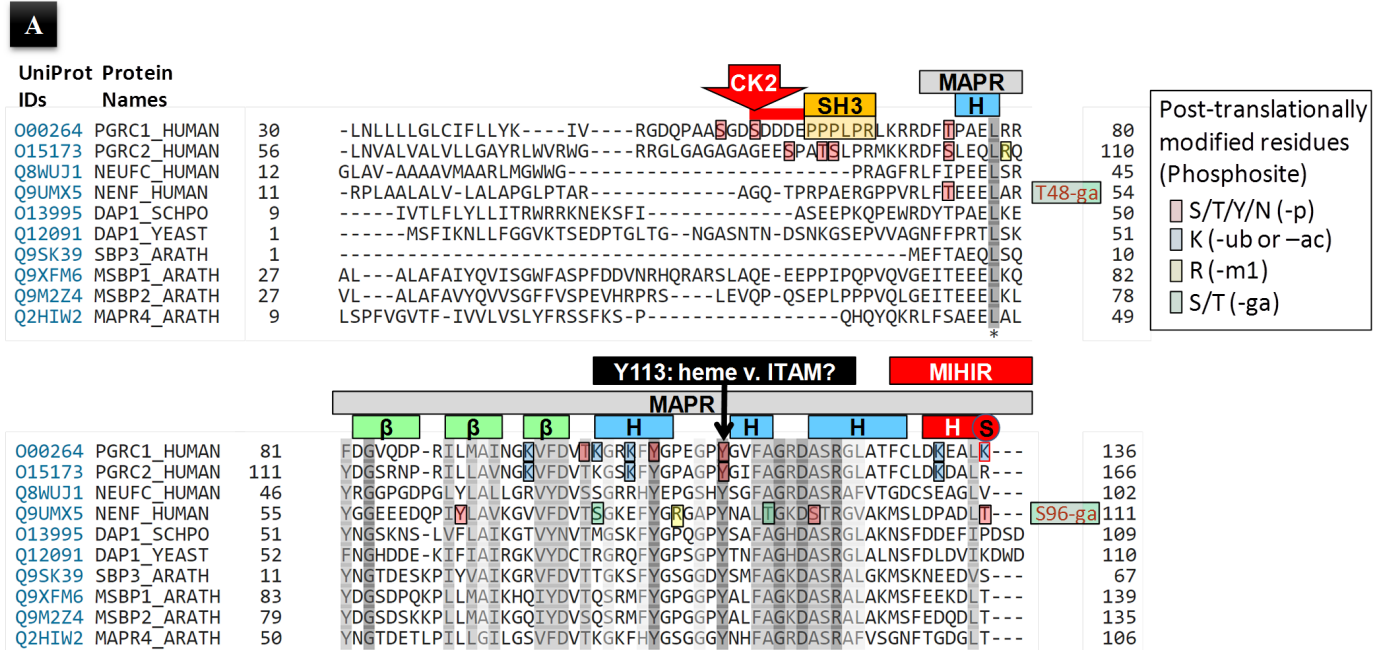

LSPFVGVTF-IVVLVSLYFRSSFKS-P----
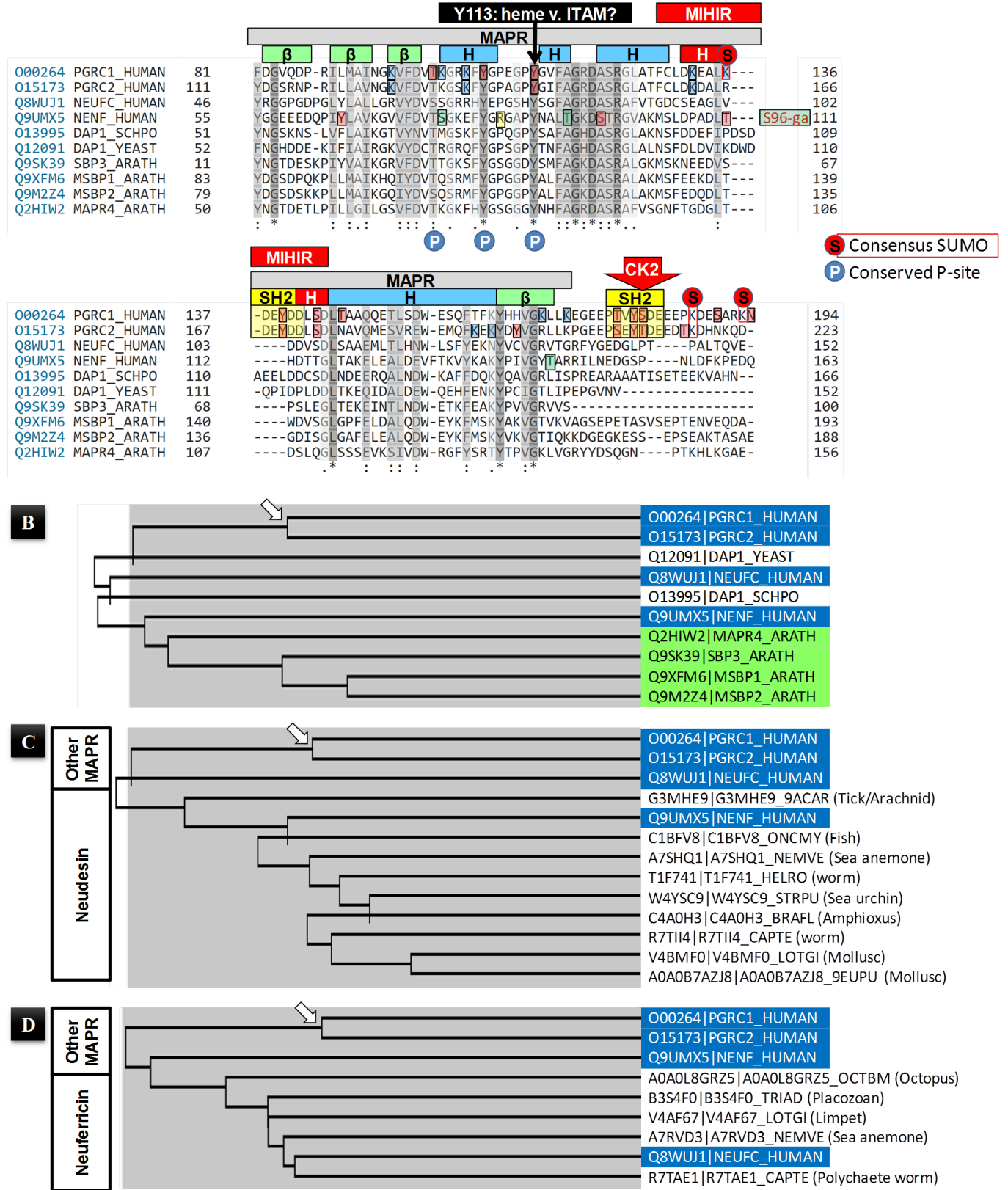

Figure 1. Sequence alignment of selected phylogenetically disparate MAPR family members, showing known posttranslational mofifications of human proteins from Phosphosite. (A) Post-translational modifications in the vicinity of the MAPR domain from Figure S1 are mapped to the amino acid sequence of the four human proteins, and aligned against 2 yeast and 4 plant MAPR proteins. The location of predicted SH2 target sequences centred on Y139 and Y180 (numbering refers to PGRMC1), and the SH3 target centred on P63 are marked. All four MAPR family proteins from human, four members from the flowering plant A. thaliana, and the single Dap1 family members from yeasts $S$. pombe and S. cerevisiae were aligned using the UniProt BLASTp tool, entering the UniProt identifiers (IDs) indicated in the figure. Similarity of amino acid properties are highlighted. The conserved cytochrome b5 domain of the MAPR family is marked by the grey box above the alignment. The positions of beta sheets $(\beta)$ or alpha helices $(\mathrm{H})$ are indicated. The half inset red bar in the cytochrome b5 domain (PGRMC1 amino acids 128-146) represents the MIHIR insertion (see text) between cytochrome b5 domain fold helices which characterizes the MAPR family $(1,13)$. Known posttranslational modifications from the Phosphosite data base (Figure S1) are included for the human proteins as indicated in the key. Blue circled P depicts phosphorylation acceptor sites conserved across all species. Red circled S depict consensus Sumoylation sites in PGRMC1 $(51,52)$. (B) The CLUSTAL similarity tree corresponding to (A). (C and D) Divergence of PGRMC1-like proteins from other MAPR proteins predates the metazoan radiation. CLUSTAL alignment of MAPR proteins from phylogenetically diverse metazoans indicates that the PGRMC1/2 clade is distinct from the Neudesin (C) and the Neuferricin clades (D). None of these families have been detected in unicellular eukaryotes (Table 1). 


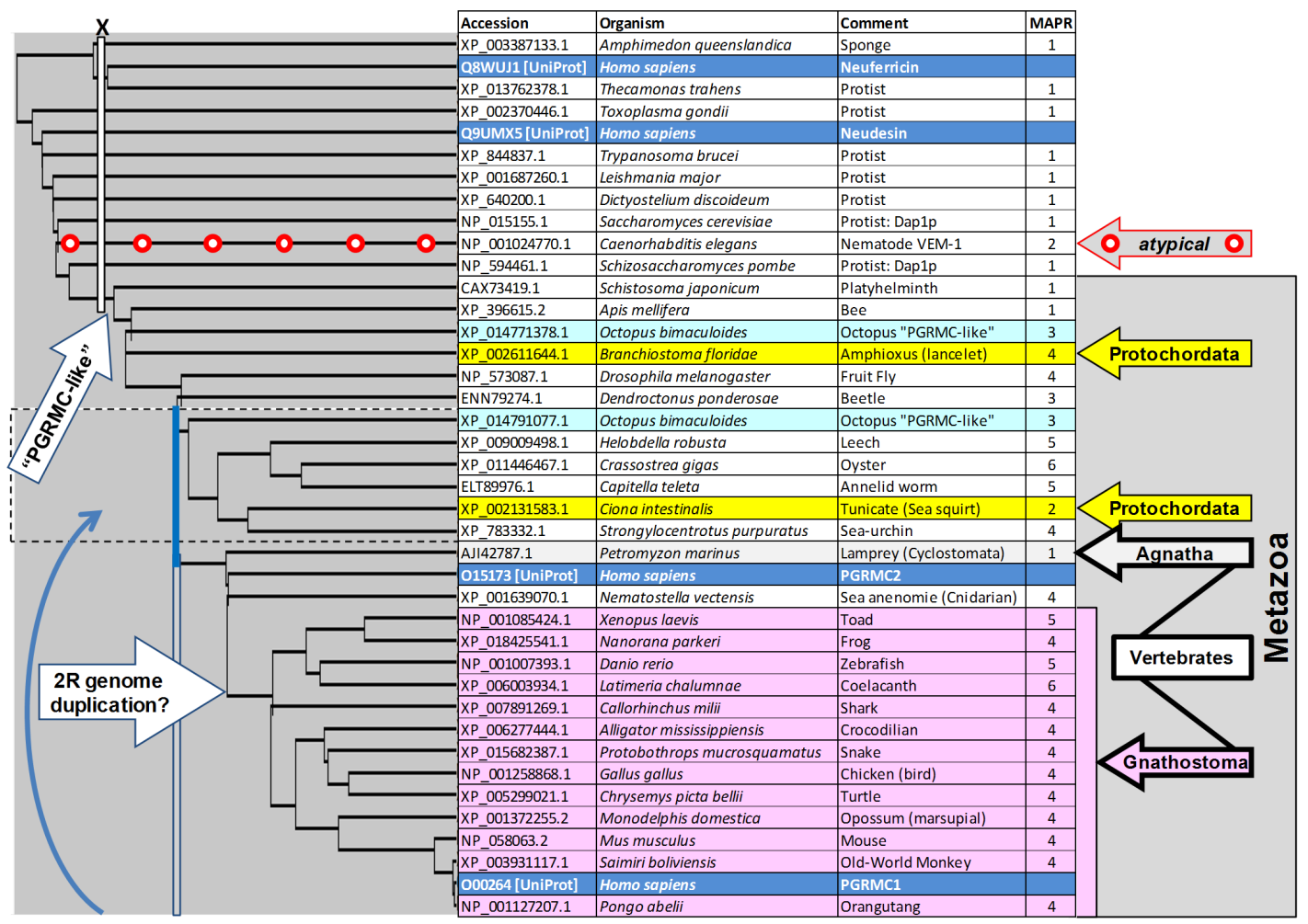

Figure 2. The phyogentic representation of PGRMC1-like MAPR proteins. Either the sole MAPR family, or the most PGRMC1like protein from each species (see Table 1) were grouped by similarity by CLUSTAL. A single exception is the octopus, where two PGRMC1-like (PGRMC-like: see Table 1) proteins are included to demonstrate that these are paralogous and not homologous to PGRMC1 and PGRMC2. i.e. octopus split from the vertebrate lineage before the divergence of PGRMC1 and PGRMC2. Therefore the octopus proteins represent a separate duplication of PGRMC-like proteins. It is not valid to speak of PGRMC1 and PGRMC2 for organisms which are not jawed vertebrates. PGRMC-like proteins appear to have arisen with metazoans. C. elegans VEMA protein is an atypical animal MAPR protein which has diverged from its metazoan ancestor (see Figure 3). PGRMC1 and PGRMC2 appear to have diverged correspondently with the emergence of jawed vertebrates, perhaps with the $2 \mathrm{R}$ genome duplication thought to have been associated with that lineage (53). For identities of MAPR proteins see Table 1. One region of the CLUSTAL alignment tree (dotted lines and curved arrow) was manually repositioned. Otherwise the CLUSTAL similarity topology has not been altered. The white bar marked "X" indicates phylogenetic separations thought by the author too deep for alignment to reasonably represent phylogeny.

2 (SH2) target motif is conserved between PGRMC1 and PGRMC2, as are various other tyrosine (Y) and serine/threonine (S/T) phosphorylation sites. The SH3target motif centred on P64, along with phosphoacceptor residues at S54 and S57, are absent from PGRMC2, and none of these motifs are present in Neudesin or Neuferricin. Alignment with other MAPR family members from human, yeast, and plant (A. thaliana) show that some potential sites of phosphorylation (PGRMC1 T101, Y107, Y113) are conserved across these MAPR proteins, whereas PGRMC1 and PGRMC2 share multiple common sites (Figure 1A).

\subsection{Posttranslational modifications of Neudesin and Neuferricin}

PTMs are documented less frequently for Neudesin and Neferricin than for PGRMC1 and PGRMC2. This may be because Neudesin and Neferricin are present in the luminal compartment and secreted extracellularly $(2,3,24-28)$, however the presence of some observed phosphorylation events suggests that the MAPR domain of these proteins may also be found in the cytoplasm. The detection of O-N-acetylgalactosamine (O-GalNAc) glycosylation does not necessarily imply an extracellular location for Neudesin, since $14 \%$ of O-GalNAc proteins are annotated with nuclear Gene Ontogeny (GO) assignments (29). Indeed the Human Protein Atlas (30) lists the main subcellular location of Neudesin as nuclear based on two antibodies using immunofluorescence and confocal microscopy in human cells (http://www. proteinatlas.org/ENSG00000117691-NENF/subcellular). It is not unknown for proteins to exhibit dual orientation of membrane toplogy, such as human CD38 antigen which exists $90 \%$ with its $\mathrm{C}$-terminus and active site in the extracellular/luminal compartment, with another $10 \%$ of protein molecules where these elements are cytoplasmic (31). Indeed the Cytb5 domain of PGRMC1 itself has been reported to be both cytoplasmic and extracellular (reviewed by (5)), such that dual membrane topology is conceivably a common feature of animal MAPR proteins.

\subsection{The invertebrate divergence of Neudesin and Neuferricin predates that of PGRMC1/PGRMC2}

Figure 1B depicts the Clustal guide tree corresponding to the alignment of Figure 1A. This is entirely based on 
Table 1. PGRMC1/2-like (PGRMC-like) proteins (which CLUSTAL groups with both PGRMC1 and PGRMC2) are found in metazoans higher than Platyhelminthes

\begin{tabular}{|c|c|c|c|c|c|c|c|c|c|c|c|}
\hline Accession & Organism & Comment & MAPR & & NEUFC-like & & NENF-like & & "PGRMC"-like & PGRMC1 & PGRMC2 \\
\hline XP_003387133.1 & Amphimedon queenslandica & Sponge & \begin{tabular}{|l|}
1 \\
\end{tabular} & & & & & & & & \\
\hline Q8WUJ1 & Homo sapiens & Neuferricin & & & & & & & & & \\
\hline XP_013762378.1 & Thecamonas trahens & Protist & 1 & & & & & & & & \\
\hline XP_002370446.1 & Toxoplasma gondii & Protist & 1 & & & & & & & & \\
\hline Q9UMX5 & Homo sapiens & Neudesin & & & & & & & & & \\
\hline XP_844837.1 & Trypanosoma brucei & Protist & 1 & & & & & & & & \\
\hline XP_001687260.1 & Leishmania major & Protist & 1 & & & & & & & & \\
\hline XP_640200.1 & Dictyostelium discoideum & Protist & 1 & & & & & & & & \\
\hline NP_015155.1 & Saccharomyces cerevisiae & Protist: Dap1p & 1 & & & & & & & & \\
\hline NP_001024770.1 & 1 Caenorhabditis elegans & $\begin{array}{l}\text { Nematode } \\
\text { VEM-1 }\end{array}$ & 2 & 1 & NP_497868.1 & 0 & & 1 & NP_001024770.1 & & \\
\hline NP_594461.1 & Schizosaccharomyces pombe & Protist: Dap1p & 1 & & & & & & & & \\
\hline CAX73419.1 & Schistosoma japonicum & Platyhelminth & 1 & 1 & & 1 & & 1 & CAX73419.1 & & \\
\hline XP_396615.2 & Apis mellifera & Bee & 1 & 1 & XP_006566840.1 & 0 & & 1 & XP_396615.2 & & \\
\hline XP_014771378.1 & Octopus bimaculoides & \begin{tabular}{|l} 
Octopus \\
"PGRMC-like"
\end{tabular} & 3 & 1 & XP_014778686.1 & 0 & & 2 & \begin{tabular}{|l|} 
XP_014791077.1, \\
XP_014771378.1
\end{tabular} & & \\
\hline XP_002611644.1 & Branchiostoma floridae & $\begin{array}{l}\text { Amphioxus } \\
\text { (lancelet) }\end{array}$ & 4 & 2 & $\begin{array}{l}\text { XP_002605720.1, } \\
\text { XP_002605719.1 }\end{array}$ & 1 & XP_002585704.1 & 1 & XP_002611644.1 & & \\
\hline NP_573087.1 & Drosophila melanogaster & Fruit Fly & 4 & 1 & NP_572535.1 & & & 3 & $\begin{array}{l}\text { NP_723757.1, } \\
\text { NP_609650.1, } \\
\text { NP_573087.1 }\end{array}$ & & \\
\hline ENN79274.1 & Dendroctonus ponderosae & Beetle & 3 & 2 & $\begin{array}{l}\text { ERL94051.1, } \\
\text { ENN78869.1 }\end{array}$ & & & 1 & ENN79274.1 & & \\
\hline XP_014791077.1 & Octopus bimaculoides & \begin{tabular}{|l} 
Octopus \\
"PGRMC-like"
\end{tabular} & 3 & 1 & XP_014778686.1 & 0 & & 2 & \begin{tabular}{|l|} 
XP_014791077.1, \\
XP_014771378.1 \\
\end{tabular} & & \\
\hline XP_009009498.1 & Helobdella robusta & Leech & 5 & 1 & XP_009019434.1 & 1 & XP_009018536.1 & 3 & \begin{tabular}{|l} 
XP_009009498.1, \\
XP_009012871.1, \\
XP_009024185.1
\end{tabular} & & \\
\hline XP_011446467.1 & Crassostrea gigas & Oyster & 6 & 3 & $\begin{array}{c}\text { EKC42144.1, } \\
\text { XP_011418616.1, } \\
\text { XP_011418617.1 }\end{array}$ & 1 & XP_011445092.1 & 2 & $\begin{array}{c}\text { XP_011446467.1, } \\
\text { EKC28875.1 }\end{array}$ & & \\
\hline ELT89976.1 & Capitella teleta & Annelid worm & 5 & 1 & ELT90457.1 & 1 & ELT93549.1 & 3 & $\begin{array}{c}\text { ELT89976.1, } \\
\text { ELU07585.1, } \\
\text { ELU07586.1 } \\
\end{array}$ & & \\
\hline XP_002131583.1 & Ciona intestinalis & $\begin{array}{l}\text { Tunicate (Sea } \\
\text { squirt) }\end{array}$ & 2 & 1 & XP_002126672.1 & & & 1 & XP_002131583.1 & & \\
\hline XP_783332.1 & Strongylocentrotus purpuratus & Sea-urchin & 4 & 2 & $\begin{array}{l}\text { XP_795139.1, } \\
\text { XP_797342.1 }\end{array}$ & 1 & XP_003727182.1 & 1 & XP_783332.1 & & \\
\hline AJl42787.1 & Petromyzon marinus & Lamprey & 1 & & & & & 1 & AJI42787.1 & & \\
\hline 015173 & Homo sapiens & PGRMC2 & & & & & & & & & \\
\hline XP_001639070.1 & Nematostella vectensis & $\begin{array}{l}\text { Sea anenome } \\
\text { (Cnidarian) }\end{array}$ & 4 & 2 & $\begin{array}{l}\text { XP_001636685.1, } \\
\text { XP_001619521.1 }\end{array}$ & 1 & XP_001628837.1 & 1 & \begin{tabular}{|l|} 
XP_001639070.1, \\
XP_001641507.1 \\
\end{tabular} & & \\
\hline NP_001085424.1 & Xenopus laevis & Toad & 5 & 1 & XP_018102462.1 & 1 & XP_018118068.1 & 3 & & NP_001085424.1 & $\begin{array}{l}\text { NP_001089766.1, } \\
\text { NP_001087737.1 }\end{array}$ \\
\hline XP_018425541.1 & Nanorana parkeri & Frog & 4 & 1 & XP_018408871.1 & 1 & XP_018409295.1 & 2 & & XP_018425541.1 & XP_018421456.1 \\
\hline NP_001007393.1 & Danio rerio & Zebrafish & 5 & 1 & NP_001096144.1 & 2 & $\begin{array}{c}\text { NP_001032793.2, } \\
\text { BAE48265.1 }\end{array}$ & 2 & & NP_001007393.1 & NP_998269.1 \\
\hline XP_006003934.1 & Latimeria chalumnae & Coelacanth & 6 & 3 & $\begin{array}{l}\text { XP_006007296.1, } \\
\text { XP_006007297.1, } \\
\text { XP_006007298.1, } \\
\text { XP_006007299.1 }\end{array}$ & 1 & XP_006013354.1 & 2 & & XP_006003934.1 & XP_005991348.2 \\
\hline XP_007891269.1 & Callorhinchus milii & Shark & 4 & 1 & XP_007909304.1 & 1 & XP_007903232.1 & 2 & & XP_007891269.1 & XP_007882916.1 \\
\hline XP_006277444.1 & Alligator mississippiensis & Crocodilian & 4 & 1 & XP_014463495.1 & 1 & XP_014453499.1 & 2 & & XP_006277444.1 & XP_006274062.1 \\
\hline XP_015682387.1 & Protobothrops mucrosquamatus & Snake & 4 & 1 & XP_015676553.1 & 1 & XP_015670150.1 & 2 & & XP_015682387.1 & XP_015674943.1 \\
\hline NP_001258868.1 & Gallus gallus & Chicken (bird) & 4 & 1 & XP_415743.1 & 1 & XP_004935389.1 & 2 & & NP_001258868.1 & NP_001006441.1 \\
\hline XP_005299021.1 & Chrysemys picta bellii & Turtle & 4 & 1 & XP_007054253.1 & 1 & XP_007058066.1 & 2 & & XP_007060285.1 & XP_007059215.1 \\
\hline XP_001372255.2 & Monodelphis domestica & $\begin{array}{l}\text { Opossum } \\
\text { (marsupial) }\end{array}$ & 4 & 1 & XP_001370477.1 & 1 & XP_001374471.1 & 3 & & XP_001372255.2 & $\begin{array}{l}\text { XP_001365574.1, } \\
\text { XP_007495566.1 }\end{array}$ \\
\hline NP_058063.2 & Mus musculus & Mouse & 4 & 1 & AAH86682.1 & 1 & NP_079700.1 & 2 & & NP_058063.2 & NP_081834.1 \\
\hline XP_003931117.1 & Saimiri boliviensis & $\begin{array}{l}\text { Old-World } \\
\text { Monkey }\end{array}$ & 4 & 1 & XP_003933104.1 & 1 & XP_010339346.1 & 2 & & XP_003931117.1 & XP_010336708.1 \\
\hline 000264 & Homo sapiens & PGRMC1 & & & & & & & & & \\
\hline NP_001127207.1 & Pongo abelii & Orangutang & 4 & 1 & XP_002826904.1 & 1 & XP_002809527.1 & 2 & & NP_001127207.1 & XP_002815179.1 \\
\hline
\end{tabular}

Neuferricin-like proteins are present in Cnidarians, nematodes, and higher animals. Neudesin-like proteins are present in worms, molluscs and chordates, but not in sampled insects. Distinct PGRMC1 and PGRMC2 proteins (as grouped by CLUSTAL) are present in jawed vertebrates (gnathostoma), but not agnathan vertebrates (lamprey) or protochordates (Amphioxus, tunicate/sea squirt). 
the pairwise alignments, and should not be confused with an evolutionary phylogeny, which it vaguely approximates for more closely related species. However it quantitatively depicts the degree of similarity between proteins (23). The degree of similarity between Neudesin and Neuferricin is similar to that between the two yeast species, which are separated by a deep phylogenetic distance $(32,33)$. All four MAPR family proteins from the plant species clustered together, consistent with their having shared a common ancestor after the monophyletic separation of plants from fungus and animals. This result suggested that the common ancestor of animal MAPR proteins was evolutionarily ancient. This was somewhat surprising, because Kimura et al. (26) reported that Neudesin was present in vertebrates, but not in the invertebrates Caenorhabditis elegans (a nematode roundworm) or Drosophila melanogaster (an insect), nor in the primitive chordate Ciona intestinalis (a sea squirt). That phylogenetic distribution would suggest that the gene for Neudesin originated in the chordate lineage leading to animals.

That interpretation seemed incompatible with the tree topology of Figure 1B. The UniProt Eumetazoan protein sequence data base was interrogated by BLASTp against human Neudesin (Figure 1C) and Neuferricin (Figure 1D) as query, revealing that sequences with greater similarity to both of these proteins are distributed across the animal kingdom, and therefore were present as separate proteins in the common ancestor of those organisms. Paradoxically, There were no BLASTp hits returned from C. elegans or D. Melanogaster, suggesting that insects and nematodes (but not arachnids or annelid worms) have lost their ancestral Neudesin genes. Therefore Kimura et al. (26) correctly reported Neudesin's absence in these species, but did not appreciate that the gene was probably secondarily lost in both lineages. Neuferricin was also widely distributed across the Eumetazoa (Figure 1D), including primitive groups such as Placazoans (B3S4F0), sea anemone (A7RVD3) Polychaete worm (R7TAE1) and molluscs (A0A0L8GRZ5, V4AF67), as well as a wide range of chordates and vertebrates but not insects (not shown), indicating that Neudesin- and Neuferricin-like MAPR proteins were present in an early metazoan ancestor.

\subsection{The ancestral Metazoan possessed a PGRMC-like $M A P R$ protein}

To examine the phylogenetic distribution of these MAPR families a series of single celled protists, and animals (metazoans) of various selected indicative phylogenetic affinities were BLASTed with NCBI BLASTp (which provides greater phylogenetic representation than UniProt) using all four human MAPR proteins together as input query sequence. The results are presented in Table 1, which indicates that all single cell level organisms screened possessed only one MAPR protein.
Platyhelminths (flat worms) possess only one PGRMClike protein that aligns most closely with the PGRMC1/ PGRMC2 group (subsequently "PGRMC-like", to denote proteins from organisms not descended from the earliest vertebrate ancestor in which PGRMC1 and PGRMC2 had diverged). Cnidarians (jellyfish and corals) possess Neferricin-like and Neudesin-like proteins by CLUSTAL alignment. Loss of Neudesin-like proteins in several higher lineages is suggested since they are absent from nematodes, insects, and octopus (mollusc), although the Oyster possesses a Neudesin-like protein, indicating that the common mollusc progenitor possessed one. Neudesin must have been secondarily lost from Octopus, which interestingly may have accommodated the loss by evolving multiple PGRMC-like proteins (Table 1).

\subsection{The PGRMC-like ancestrally inherited metazoan protein diverged into PGRMC1 and PGRMC2 in the lineage leading to vertebrates}

The jawless vertebrates Amphioxus and the lamprey have only one PGRMC-like protein. The lamprey has presumably secondarily lost its other ancestral complement of MAPR genes, since it has only a single PGRMC-like MAPR gene (Table 1). Jawed vertebrates exhibit at least two distinct PGRMC-like proteins which each clustered closer to either PGRMC1 or PGRMC2, indicating that the PGRMC1/PGRMC1 gene duplication event occurred in the lineage that gave rise to jawed vertebrates.

The same organisms as Table 1 are shown in Figure 2 along with the CLUSTAL alignment trees for the alignment of the most PGRMC1-like protein in each organism. Table 1 includes the single most PGRMC1like protein per organism (with two exceptions, being human, where all four MAPR proteins are included, and octopus, to demonstrate that the two anciently diverged PGRMC-like proteins do not cluster more closely to either PGRMC1 or PGRMC1). The gene divergence that gave rise to PGRMC1 and PGRMC1 had not occurred in the organism that gave rise to molluscs and vertebrates. Therefore it is fallacious to refer to separate homologues of PGRMC1 and PGRMC2 for non-vertebrate organisms.

Figure 2 and Table 1 reveal that PGRMC-like proteins are shared by metazoans but not protists, and that PGRMC2 is most similar to lamprey, sea anenome and then the vertebrate PGRMC1 group (Figure 2), reinforcing that the PGRMC1/2 divergence occurred prior to the vertebrate radiation. Note that the Ceanorhabditis elegans VEM-1 protein atypically clusters with protist MAPR proteins, which will be considered below.

3.6. The ancestral animal PGRMC-like protein contained a tyrosine C-terminally to the MAPR domain corresponding to PGRMC1 Y180 


\section{$\mathbf{A}$}

000264 PGRC1_HUMAN NP_-001127207.1_orangu. . XP_-003931117.1_sq-mon. NP_058063.2 mouse

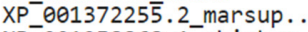
NP 001258868.1 chicken XP-006277444.1-alliga. XP 015682387.1 snake XP-005299021.1-turtle. NP- 001085424.1 Toad (Xenopus) XP-018425541.1 frog-N NP- -1007393 - fish XPXP_-06003. XPO15173 PGRC2_HUMAN AJI42787.1_lamprey XP_ө02611644.1_Amphio.. XP_o02131583.1_sea-sq. XP_783332.1_sea-urchin ENN̄79274.1_beetle XP_396615. 2 bee NP $573087.1^{-}$fly XP- $01144646 \overline{7} .1$ oyster XP 014791077.1 Octopus 1 XP-014771378 1-Octopus2 ELT̄89976.1 ann'-lid $X P$ P NP-001024770.1- leech XP-O [VEM-1] X $\bar{x} 734100.1$ CAX73419.1 Schistosom. XP_O丶万נ387133.1_sponge XP_-02370446.1_toxopl. XP_844837.1_Trypanosoma XP_001687260.1_Leishm. . XP_640200.1_Dictyoste. . NP_594461.1_S-pombe NP 015155.1 S-cerevis. XP- $01376237 \overline{8} .1$ Thecam. .

MHIR $\$$ S143 Y139SH2 MAPR domain

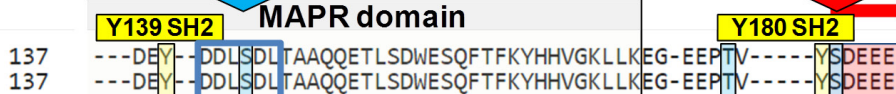

137 - DEY-DDLSDLTAAQQETLSDWESQFTFKYHHVGKLLKEG-EEPTN- - - YSPEEE

137 --DEY-DDLSDLTAAQQETLSDWESQFTFKYHHVGKLLKEG-EEPT V-..-YYSPEEE

137 - - DEY-DDLSDL TPAQQETLSDWDSQFTFKYHHVGKLLKEEG-EEPTV-..-YSDDEE

136 - - DEY-DDLSDL NATQQETLKDWESQFTFKYHYVGKLLKEG-EEPTK - - - YSPDEG

135 - - DDY-DDLSDL NATQQETLRDWESQFTFKYHHVGKLLKDG-EEPT V-..-YSSEEE

130 ---DEY-DDLSDLPATQQETLQDWESQFTFKYPCVGKLLKEG-EEPT -...

129 - - DEY-DDLSDLNATQQETLRDWESQFTFKYHYVGKLLKEG-EEPTV-.--YYSPEEE

118 -- DTD-DDLSDLTATQKETLNDWEEQFTFKYHHVGKLLKAG-EEPTE---- YTPDED

- -DTY- DD SDL TASQRETLSDWEQQFTFKYHHVGKLLKDG-EEPTE---- YPEED

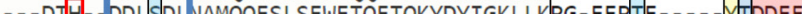

- D

- D

--DEY-DD SDL NAMQQESLQEWMQF TKY

- DE DD D T

- - EGY-DDLSDM SPTEMESVYEWEMQFTEKYHHVGRLLKPG-EEPNE--- MISDTES

-.-DEY-DDLSDL NAMQWESIREWEQQFQGGAYSHRMNLKKTPALSIS-..--LK-..-

- -DGY-DDISDL NAMEMESVREWEMQFSEKYEFIGKLLKPG-EEPTP-..-YYSDFSE

--DEF-DELSDL TSEQMDSVREWEMQFMEKYDYIGKLLKPN-EEPID-----YSDEEE

- - DQY - DDLSDLSTLEMDSVREWETQFNEKYDYVGRLLKPG-EQPNN - - - YSDEED

- -QEY-DDLSDLKTGEMESIREWEEQFKEKYDYVGRLLKPG-EAPTN- - - YSDEED -- DEY--DDLSDL SAVEMDSVREWEMOFKEKYELVGKLLRKG-EEPTN----MDDDED - -DEY-DDLSDL TSMQMESVREWEMOFTEKYDYVGQLLKPG-EVPHD-- - -YTDTED - - NEY--DDLSDLTSAEMSRMOEWEMOFTEKYDIVGKLLRDG-EOPTE--.--YTDSED - - -DGY- DDLSDLTSSOMNQIHEWEMOLTDEYTLVGRLLOPG-OOPID - . - - MTPSED -DEY- - DDLSDL ISMOMESTHEWEMOFTEKYDYVGRLLYAG-EEPTD--.-- YTPTEE D -.-SEW- DDHTGIS SADEQETANEWETOFKFKYLTVGRLVKNS-SEKAD-... Y GNRKS - - DEY-DDLSDL VGMOODSLREWEOOFDEKYDLVGRLLKPG-EKHQQ- - - Y Y ETEEE . - DEY- DDLSDL TADOMKTLREWELOFSERYDHIGRLLKPG-EPHRI ..... YEINDG

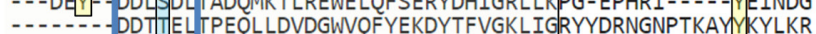
---TVP--SKWQTLSPDENETIDDWEERFKAKYDHVGFVVFGVPAEDALLREM-YSEERK 作 ---QPWTNQSLDDLTADQKDSLKNWIDFFSERYTLVGNVKE SDAEEL--DDCSDLNDEERQALNDWKAFFDQKYQAVGRLISPR-EARAA----A ISET WD-QPI --DPLDDLTKEQIDALDEWQEHFENKYPCIGTLIPEP-GVNVA

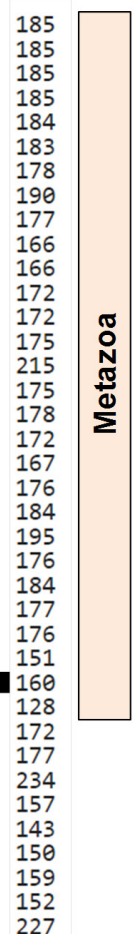

B

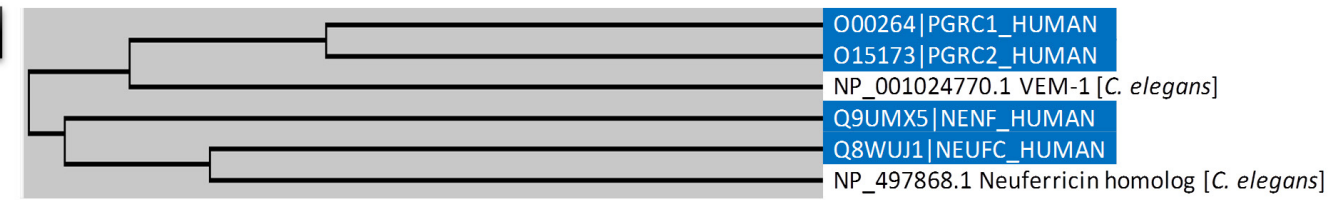

Figure 3. SH2 target motifs centred on Y139 (numbering refers to PGRMC1) with adjacent phosphorylatabel residue at S143 and at Y180 C-terminal to the MAPR domain and an adjacent CK2 site present at the dawn of metazoan evolution. (A) The appearance of PGRMC1 S/T position 143 and Y180 predated metazoan evolution. Proteins and species are the same as Table 1 and Figure 2. Note that C. elegans VEM-1 (black arrows) is an atypical animal PGRMC-like protein, exhibiting disruptions in both elements. (B) Although atypical (A), C. elegans VEM-1 is a "PGRMC-like" protein. Note that NCBI BLAST revealed a C. elegans 964 residue protein sequence "PIR: H89582 protein K07E3.6" [imported from UniProt] with a region of 100\% identity to VEM-1. BLAST of UniProt version August 4, 2016 with H89582 revealed a protein Q21286 Probable cation-transporting ATPase K07E3.7 (Gene K07E3.7/K07E3.6) lacking the VEM-1 sequence. Therefore NCBI sequence H89582 is a presumed database artefact and is excluded from this study.

Figure 3A shows the CLUSTAL amino acid alignment of the MAPR proteins from Figure 2 and Table 1, for the region aligned with human PGRMC1 residues 137-185 (all amino acid numbering refers to the corresponding aligned residue of human PGRMC1), which contains both SH2 target motifs, and includes conserved phosphorylation sites at Y139, S143, T178, Y180 and S181 (Figure S1, Figure 1).

The appearance of a Y residue corresponding to Y180 (or at least proximally $\mathrm{C}$-terminal to the MAPR domain) is shared by animals and some protists, suggesting that tyrosine phosphorylation immediately C-terminal of the MAPR domain may have provided a level of regulation that was important for an inferred ancestral PGRMC-like function in some protists, including those which gave rise to animals, which has retained selectional importance throughout animal evolution. To my knowledge, this is the first such phosphorylation event inferred to have been developed for any protein in the protist eukaryotic group that gave rise to animals, and has been conserved throughout animal evolution.

\subsection{The ancestral animal PGRMC-like protein contained both SH2 target motifs}

Interestingly, animals and sponges share a PGRMC1 "DDLSDL" motif containing S143 (Figure 3A). The phylogentic appearance of PGRMC-like proteins in the animal lineage (Schistosoma and higher) corresponds with the appearance of the DEY motif of Y139 at the level of the platyhelminth Schistosoma. Sea anenome and higher organisms also share a patch of negatively charged residues and a phosphorylatable residue immediately C-terminal to Y180, corresponding to the 


\begin{tabular}{|l|l|l|}
\hline Accession & Organism & Comment \\
\hline O00264 [UniProt] & Homo sapiens & Human PGRMC1 \\
\hline NP_001127207.1 & Pongo abelii & Orangutang \\
\hline XP_003931117.1 & Saimiri boliviensis & Old-World Monkey \\
\hline XP_014439595.1 & Tupaia chinensis & Chinese tree shrew \\
\hline NP_058063.2 & Mus musculus & Mouse \\
\hline XP_001372255.2 & Monodelphis domestica & Opossum (marsupial) \\
\hline NP_001258868.1 & Gallus gallus & Chicken (bird) \\
\hline XP_006277444.1 & Alligator mississippiensis & Crocodilian \\
\hline XP_015682387.1 & Protobothrops mucrosquamatus & Snake \\
\hline XP_005299021.1 & Chrysemys picta bellii & Turtle \\
\hline NP_001085424.1 & Xenopus laevis & Toad \\
\hline XP_018425541.1 & Nanorana parkeri & Frog \\
\hline NP_001007393.1 & Danio rerio & Zebrafish \\
\hline
\end{tabular}

Start AA
52
52
52
51
52
51
52
46
57
47
37
37
43

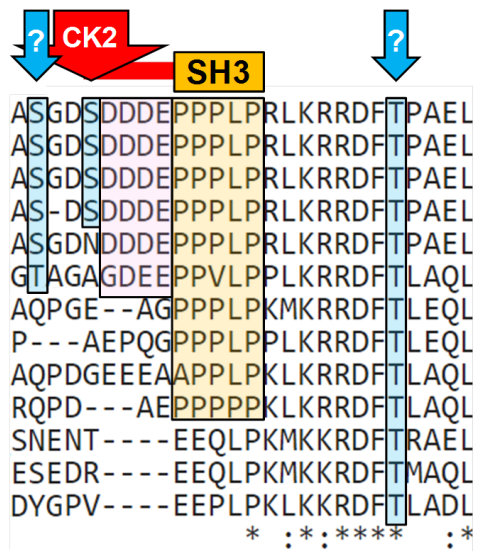

Figure 4. The PGRMC1 SH3 target motif centred on P64 (numbering refers to PGRMC1) with an adjacent CK2 site is present in the primate lineage. The proline-rich SH3 target motif is present in all land vertebrates which evolved from amphibians. A phosphorylatable residue appears C-terminally at the S54 position in marsupials and mice, which is augmented by an adjacent CK2 consesus site (SDDDE) present in the primate lineage from shrews to apes. The phosphorylation site at T74 is highly conserved (Figure S1A), but of unknown function.

superposition of the S181 CK2 site motif upon the Y180 SH2 target motif (Figure 3A).

Annelid worms and molluscs, and other higher organism in Figure 3A additionally exhibit the adjacent T178 phosphorylation site in their PGRMC-like protein, which was variously lost in some lineages, but which became absolutely conserved in vertebrates, and therefore presumably performs some function enabling the complexity of PGRMC-like protein regulation required for vertebrate biology.

\subsection{C. elegans VEM-1 is an atypical PGRMC-like protein}

It becomes apparent why VEM-1 clusters away from other animal PGRMC-like proteins in Figure 2, because it lacks the Y139 and C-terminal negatively charged CK2-like motifs, which we can deduce were secondarily lost from the ancestral PGRMC-like condition in the nematode lineage. Alternatively, VEM-1 could be descended from a non-PGRMC1-like protein. To test this situation both $C$. elegans MAPR proteins were aligned with all four human MAPR proteins (Figure 3B). The alignment of VEM-1 with PGRMC1 and PGRMC2 clearly identifies it as a PGRMC-like protein which is distinct from the Neuferricin homologue (Figure 3B), but which has lost some hallmark PGRMC1-like features (Figure 3A). Note that $C$. elegans therefore does not have PGRMC1 and PGRMC2 homologues, but rather a PGRMC-like gene and a Neuferricin-like gene. It has also lost its ancestral Neudesin-like gene (Table 1).

\subsection{The PGRMC1-specific SH3 target motif is shared by terrestrial tetrapods}

The N-terminal regulatory cytoplasmic region of PGRMC1 is not shared with PGRMC2, and therefore arose after their gene divergence. The conserved
PGRMC1 phosphorylation site at T74 in Figure 4 is shared with PGRMC2 (Figure 1A), however with the appearance of terrestrial tetrapods (reptiles including birds, and mammals, but not amphibians) a prolinerich sequence centred on P64 appeared. Placental and marsupial mammals, but not birds or reptiles, possess the phosphorylatable reside at T54, and all placental mammals have acquired the negatively charged DDDE motif immediately C-terminal to the proline-rich patch. The poly-negative charge probably influences the specificity of $\mathrm{SH} 3$ domain proteins that can interact with the adjacent proline-rich sequence. In the primate lineage this motif is further garlanded by the appearance of S57, to create the CK2 motif that is thought to sterically prevent interaction of $\mathrm{SH} 3$-domain proteins to the proline-rich SH3-target motif when phosphorylated $(13,20,21)$, and provide new levels of finesse to the regulation of PGRMC1 function.

In summary, a new binding site for one or more SH3 domain proteins appeared on PGRMC1 as vertebrates colonised the land. In the mammalian lineage leading to humans this motif was equipped with the means for increasingly sophisticated regulation. It is currently unknown which biological processes are governed by such regulations. Possible functions which differ between the organisms involved include embryogenesis, skin ultrastructure including hair formation, properties of the ovaries/eggs, lactation, oestrus, and many more. Clearly an imperative research priority should be to develop reagents to assay for the state of phosphorylation of this and other PGRMC1 motifs to gain deeper understanding of its potential role in these foundational vertebrate processes.

PGRMC2 is fundamentally different to PGRMC1 in this region (Figure 1A). It should be equally important to determine which processes these two proteins can affect uniquely or in common, whether their effects on common processes are in the same directions, and the 


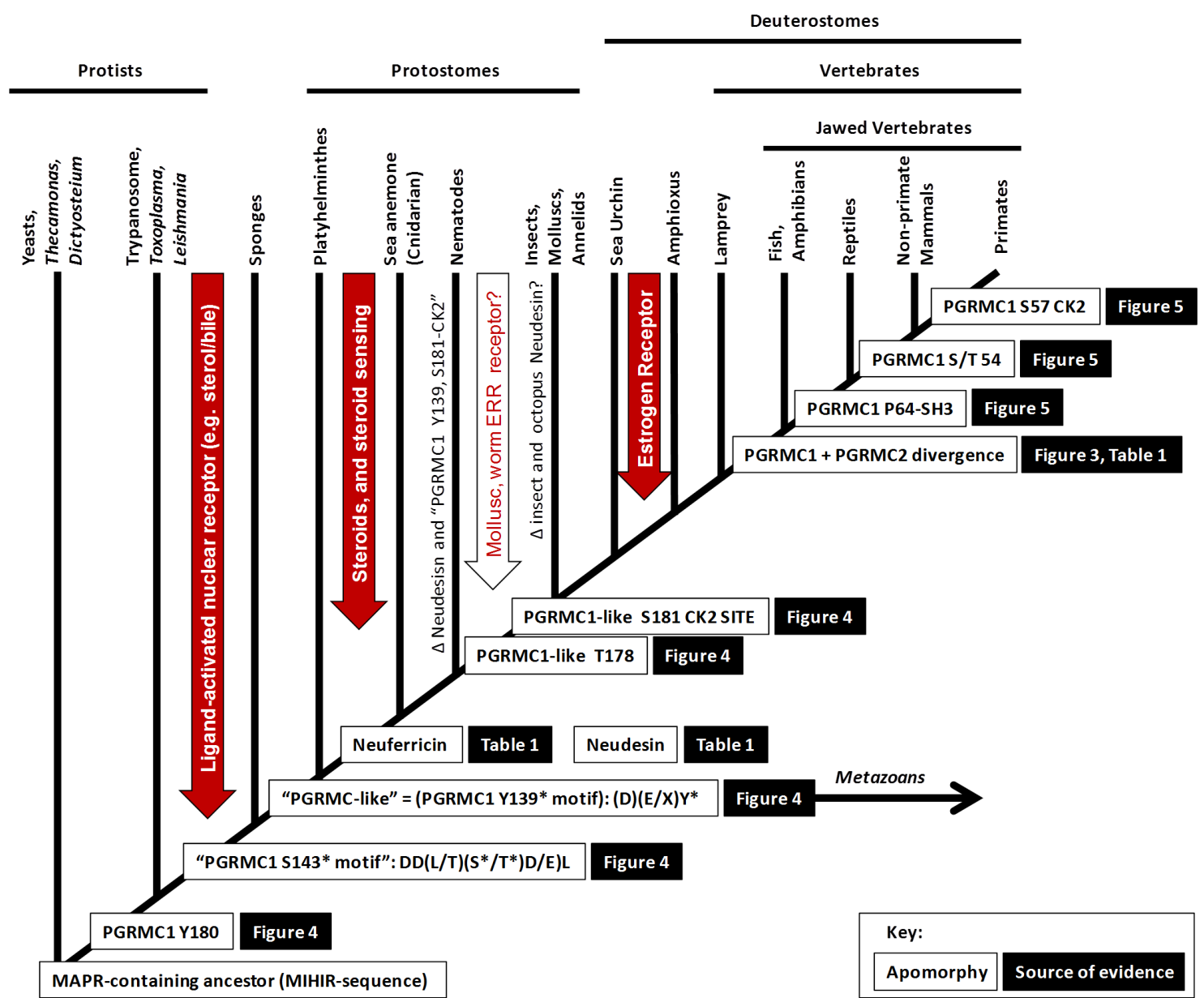

Figure 5. A cladogram of eukaryotic organisms considered in this study based upon MAPR-family traits. The single celled eukaryotic ancestral organism to all organisms considered contained a MAPR family gene, called the the plesiomorphic condition. Apomorphies, or shared derived character states, are indicated on the cladogram stem with their source in black boxes. Amino acid numbers refer to motifs with reference to PGRMC1. The question mark (?) is present because a symmetrical segmented wormlike body plan is thought to have predated insect development, and because octopus and oysters are thought to be part of the same monophyletic evolutionary mollusc clade. This emphasizes the point that this is not a valid evolutionary tree, but a cladogram based solely upon inherited MAPR-related traits, and the appearance of steroids and steroid receptors (ERR, Estrogen related receptor; ESR estrogen receptor) following Baker (16) and Markov et al. (14) (vertical downward arrows) to separate some clades. Sea urchin is separated from protostomes by virtue of being a deuterostome (i.e. not by MAPR- or steroid-related traits).

molecular basis underlying any different functions.

\subsection{Animal evolution topologically aligns with MAPR apomorphies}

The above derived character traits of the MAPR family can be used to construct a cladogram based upon the appearance of new character states (apomorphies). Different organisms which inherit the same apomorphy share a synapomorphy which defines monophyletic groups of taxa (clades) which are descendants of the ancestral organism in in which the apomorphy first appeared (34). The cladogram of Figure 5 relatively accurately corresponds with known phylogeny of evolutionary divergence of these groups. Because of the association of PGRMC1 with P4 responsiveness, the cladogram has also been augmented by information about the evolutionary origins of ligand activated receptors, steroid production and sensing, and the appearance of the Estrogen receptor in protochordates (Amphioxus in Figure 5), as referenced from Markov et al. (14). One interpretation of this cladogram is that the development of increasingly sophisticated regulation of PGRMC-like protein function throughout animal evolution has been intimately involved with the development of the key features which define these different lineages, right up to primates. In this model, PGRMC-like proteins provided some quintessential function to higher eukaryotic cell biology, and the tweaking and fine tuning of the MAPR/ PGRMC1 functional axis has been a powerful driving force throughout the diaspora of animal evolution. If so, it appears that the regulation of PGRMC-like proteins by phosphorylation (21) has been at the very heart of this evolutionary process.

This concept implies that animal evolution has involved regulated phosphorylation of unknown 
signalling events based upon the Y180 motif of PGRMClike proteins since our Precambrian ancestors. The motif was subject to increasingly sophisticated regulation during early animal evolution, particularly involving gain of the T178 site and its subsequent loss in several lineages. However, it appears to have been absolutely conserved in both PGRMC1 and PGRMC2 since their divergence prior to the origin of jawed vertebrates (Figure $3 \mathrm{~A}$, Figure 5), after which protein interactions with the PGRMC1 proline-rich SH3 motif appeared and became subject to increasingly complex regulatory possibilities (Figure 4, Figure 5).

\section{Discussion}

\subsection{PGRMC or MAPR family?}

McCallum et al. (35) referred to the MAPR family as the "PGRMC family". In this present paper I argue for the presence of PGRMC-like, Neuferricin-like, and Neudesin-like metazoan MAPR proteins, which are specific for animals (metazoan) but not other eukaryotes. "PGRMC-like" proteins (as defined here) are then a specific sub-clade of the MAPR family which does not include protist MAPR proteins. To avoid terminological confusion I refer to the MAPR family to denote the group of MIHIR-containing Cytb5 proteins. "PGRMC-like" better refers to those metazoan MAPR proteins which ancestrally contained the equivalent of PGRMC1 Y139, S143, and Y180. Neuferricin appears to have evolved by gene duplication of the PGRMC-like gene followed by loss of the Y180 homologous residue. Neudesin appears to have similarly later diverged prior to the divergence of Protostomes and Deuterostomes, from probably Neuferricin however that is uncertain (Figure 1B-D, Figure 3B, Figure 5, Table 1). All four MAPR proteins were present in the ancestor of annelids and molluscs, whereas ancestral Neudesin appears to have been lost from insects. Therefore use of the term "PGRMC family" (35) to denote the MAPR family appears to introduce room for potential systematic confusion.

\subsection{Progesterone responsiveness of PGRMC-like proteins is likely a vertebrate phenomenon}

Participation of MAPR proteins in cholesterol synthesis is a function shared from protist to metazoan eukaryotes (11), which we can conclude was inherited from the earliest eukaryotic cell. Steroid hormones arose much later in evolution, presumably in the metazoan lineage. Both vertebrates and invertebrates possess ligandactivated classical/nuclear receptors for hydrophobic ligands such as terpenes, fatty acids, eicosanoids, sterols and bile acids, most of which are products of the mevalonate/isoprene pathway $(15,36)$. From such a commonly inherited sterol sensing mechanism, separate clades are thought to have convergently evolved steroid signalling mechanisms based upon cnidosteroids (cnidarians such as jellyfish and corals), lophosteroids (annelid worms, molluscs, etc), ecdyosteroids (insects, other arthropods, and nematode worms), and vertebrosteroids (vertebrate lineage, commencing from an original ESR gene) (14). These steroid signalling systems evolved independently from one another in those clades in a striking example of parallel evolution.

The main steroidogenic CyP450 enzymes (37) as well as adrenal and sex steroid receptors (15) both recognizably arose in the protochordate lineage leading to vertebrates, with subsequent receptor gene duplications and functional diversification throughout vertebrate evolution (15). The estrogen receptor (ESR) was the first vertebrate steroid receptor (Figure 5), from which subsequent gene duplications eventually produced the classical progesterone receptor (14).

The enzyme P450 side-chain cleavage enzyme (P450scc, CYP11A1), which catalyzes the synthesis of the first vertebrate steroid hormone pregnenolone from cholesterol in mitochondria, has low sequence conservation (37), and therefore may not be recognizable in lower organisms. However, extensive BLAST analysis of lower organisms has not identified CYP11A1 in organisms lowere than Amphioxus (14), and pregnenolone has not been convincingly reported in invertebrates to date (14).

From the above consideration, we can conclude by process of deductive logic that if sterol sensing arose in metazoans, and if steroid synthesis involving P4 appeared first in the vertebrate lineage, then any P4 or even progestogen sensing or signalling function of PGRMC1 is probably not an ancestral MAPR function. MAPR proteins do share an ancestrally inherited role in sterol synthesis (11). If an ancestral PGRMC-like protein participated in sterol sensing or sterol transport that involved low affinity interactions with cholesterol or derivatives, it is quite feasible that it could have secondarily acquired responsiveness to progesterone/ progestagens once they appeared. (However whether PGRMC1 itself acts as a direct P4 receptor itself is still unclear (5).) Indeed, the ancestral metazoan nuclear steroid receptor is thought to have similarly originally been involved in sterol sensing, as well as being able to bind a broad range of metabolites including dietary sterols and xenobiotics. That activity had evolved into an ESR activity by the time the vertebrate estrogen synthetic pathway had evolved, and there is still some overlapping ligand affinity of certain modern steroid receptors for specific steroids and other hydrophobic ligands (14).

\subsection{Axonal migration probably does not involve PGRMC-like SH3 or SH2 target motifs}

PGRMC1 is involved in directing the axonal migration of nerve cells in the embryologically developing nerve chord of nematodes and humans (17-19). Interestingly, 
the lack of the Y139 motif and the S181 CK2 site from VEM-1 (Figure 3A) most probably mean that these motifs are not involved in that function exerted by PGRMC1, although we cannot be certain. VEM1 interacts with members of Netrin-receptor family in C. elegans (18), and presumably in other animals in such a conserved process of body plan definition. The membrane trafficking function of PGRMC1 (reviewed by (5)) may be involved in regulating the cell surface expression of Netrin receptors to enable axon guidance in this process. Because they are the only major MAPR phosphorylation sites conserved between mammals and nematodes, presumably either Y113 (which contains a presumed membrane trafficking motif $(5,21)$ ) or Y107 are involved in this process. However that hypothesis requires experimental confirmation. This thought process demonstrates how systematic approaches such as this study can guide us to begin to functionally separate and stratify different pathways of the mutinodal signal integration web that is suspected to revolve around the fulcrum of PGRMC1 function (5). Indeed a central axis involving PGRMC1 Y180 is now revealed as running right back to single celled Precambrian biology.

Other intruiging PGRMC1 functions, in terms of cellular life as part of a multicellular organism, are controlled cell death, and hormonal signalling (reviewed by (5)). PGRMC1 confers resistance to death-inducing signals to some cells, and also confers responsiveness to progesterone (P4) and related progestogens. It is highly likely that these functions are separate to axonal migration guidance, and variously controlled by the different regulatory modules described here. It will be most interesting to see whether the observed co-evolution of a suite of mitochondrial genes with PGRMC1 (8) is related to any role of PGRMC1 in directing mitochondrial function, especially the changes in mitochondrial function that are associated with progression from single celled oocyte and zygote through embryogenesis towards a multicellular orgnanism (38). These reflect the changes in mitochondrial function required in the evolutionary progression from protist eukaryotes to metazoans as considered in this paper.

\subsection{Is the PGRMC1/Sigma 2 Receptor function related to multicellularity?}

The Sigma 2 Receptor (S2R) is an unidentified receptor activity that binds a large number of hydrophobic S2R ligands associated with neural disorders and cancer (39). Sigma receptors were originally described in 1976 as a subtype of the opiate receptor, based on the properties of ( \pm )-SKF-10,047 (N-allylnormetazocine) and the structurally related analogues morphine and ketazocine. This led to the classification of three opiate receptor subtypes, $\mu$ for morphine, $\kappa$ for ketazocine, and $\sigma$ for ( \pm -SKF-10,047. It was subsequently found that the (-) stereoisomer of SKF-10,047 bound to the $\mu$ and $\kappa$ opiate receptors. However the $(+)$ isomer bound to an unknown non-opiate receptor, which became known as the $\sigma$ (Sigma) receptor. Various ligands were found to bind this enigmatic receptor, some of which revealed that there were two distinct proteins with $\sigma$ receptor activity, which became known as $\sigma 1$ (S1) and $\sigma 2$ (S2) receptors (reviewed by (39)). The sigma 1 receptor (S1R) was cloned in 1996, and found to have low homology with a sterol isomerase (40). It has been reported to be involved in lipid transport, the regulation of cholesterolrich lipid raft microdomain formation at the plasma membrane, and the metabolism of cholesterol-containing cytoplasmic lipid droplets (41). S1R possesses protein chaperone function, where it provides an ER luminal hydrophobic binding site which binds to and stabilizes certain proteins, and which is located at cholesterolrich ER regions, including mitochondria-associated ER membranes and the ER-cytoplasmic membrane interface (42). Like PGRMC1 (12), S1R is also associated with Insig-1, where S1R is implicated in the ER-associated degradation of proteins in a possibly sterol-dependent manner $(42,43)$.

The identity of S2R remains unknown, however radio-ligand studies have shown that its activity was upregulated 10 -fold in proliferating compared to quiescent cancer cells. In addition, certain S2R ligands bound their receptor at the cell surface, translocated to the mitochondrion, and killed tumor cells via both apoptotic and nonapoptotic mechanisms $(39,44)$, which indicates an essential function for the S2R in some cancers. S2R ligands were internalized by both phenyl arsine oxide inhibitable receptor-mediated endocytosis, as well as via undefined non-inhibitable mechanism such as passive diffusion or non-receptor-mediated endocytosis (45).

In 2011 PGRMC1 was identified by Mach and colleagues as being part of a protein complex with S2R (46). A photoaffinity-labeled S2R ligand was cross linked to PGRMC1, indicating that PGRMC1 must be present with intimate proximity in an S2R-containing protein complex (46). In several cell types, but not all, PGRMC1 is required for S2R activity. This led to some confusion as to the possible identity of S2R and PGRMC1 (for review: (5)), which remains formally unresolved. However S2R is probably a separate $18 \mathrm{kDa}$ protein unrelated to PGRMC1 (5).

S2R activity is vitally important for many cancer cells (39), and is associated with cancer stem cell properties related to proliferative status and survival (4749). It is conceivable that this PGRMC1-S2R system, that regulates differentiation, proliferative, and survival decisions, reflects a remnant of the ancestral control of replication of the primitive single celled eukaryote. Thereby, the requirement of cancer and cancer stem cells for S2R activity may represent an ancestral S2R unicellular replication licensing function, which is modulated by PGRMC1-like proteins in metazoans that must impose strict restraints on proliferative activity. 
If so, the PGRMC1 Y180 and/or the Y139 SH2 target motifs are probably involved since these originated with the appearance of multicellularity. The verification or falsification of this prediction must await the identification of the $18 \mathrm{kDa}$ PGRMC1-associated protein which contains the S2R activity (for review: (5)).

\section{Conclusions}

Signalling and regulatory motifs on the PGRMC1 protein are shown here to have evolved along with animals during the metazoan radiation. This study portrays PGRMC1 as a cornerstone protein with functions central to eukaryotic biology and the origin of multicellular animals, that is potentially able to dramatically alter eukaryotic cell biology because of the deep evolutionary dependence of multiple cell functions upon MAPR proteins. If PGRMC1 regulates functions operating at a foundational cornerstone level of cell biology, then those alterations could have wide ranging pleiotropic effects relating to the strictures of multicellular life. Just as Archimedes thought to move the world with a fulcrum and a sufficiently large lever, so PGRMC1 phosphorylation could exert either tremendous metaphorical leverage, or occupy a cellular fulcrum with roots in the Precambrian. Obviously, such pleiotropic properties could be highly problematic for healthy biology when usurped by pathological processes such as cancer $(5,20)$ or Alzheimer's disease $(50)$. This raises the spectre that it is perhaps not the expression level of PGRMC1 which is most important to disease, but its state of modification. Since practically nothing is known about PGRMC1 modifying enzymes, this highlights an area which requires urgent investigation.

\section{Acknowledgements}

This work has received no direct Australian competitive grant support since 2008. This work was supported by Charles Sturt University (CSU) School of Biomedical Sciences (SBMS) Compact grant A541-900-xxx-40513, SBMS support A534-900-xxx-41066, and CSU Competitive grant A102-900-xxx-40002, all to MAC. The funder had no role in study design, data collection and analysis, decision to publish, or preparation of the manuscript. This publication reflects only the author's views. The funder is not liable for any use that may be made of the information herein.

\section{References}

1. Mifsud W, Bateman A. Membrane-bound progesterone receptors contain a cytochrome b5-like ligand-binding domain. Genome Biol. 2002; 3:Research0068.

2. Hasegawa S, Kasubuchi M, Terasawa K, Kimura I. Perspectives On Membrane-associated Progesterone Receptors As Prospective Therapeutic Targets. Curr Drug Targets. 2016; 17:1189-1197.
3. Kimura I, Nakayama Y, Konishi M, Kobayashi T, Mori M, Ito M, Hirasawa A, Tsujimoto G, Ohta M, Itoh N, Fujimoto M. Neuferricin, a novel extracellular hemebinding protein, promotes neurogenesis. J Neurochem. 2010; 112:1156-1167.

4. Petersen SL, Intlekofer KA, Moura-Conlon PJ, Brewer DN, Del Pino Sans J, Lopez JA. Nonclassical progesterone signalling molecules in the nervous system. J Neuroendocrinol. 2013; 25:991-1001.

5. Cahill MA, Jazayeri JA, Catalano SM, Toyokuni S, Kovacevic Z, Richardson DR. The emerging role of progesterone receptor membrane component 1 (PGRMC1) in cancer biology. Biochim Biophys Acta. 2016; 1866:339-349.

6. Piel RB, 3rd, Shiferaw MT, Vashisht AA, Marcero JR, Praissman JL, Phillips JD, Wohlschlegel JA, Medlock AE. A Novel Role for Progesterone Receptor Membrane Component 1 (PGRMC1): A Partner and Regulator of Ferrochelatase. Biochemistry. 2016; 55:5204-5217.

7. Ghosh K, Thompson AM, Goldbeck RA, Shi X, Whitman S, Oh E, Zhiwu Z, Vulpe C, Holman TR. Spectroscopic and biochemical characterization of heme binding to yeast Dap1p and mouse PGRMC1p. Biochemistry. 2005; 44:16729-16736.

8. Cahill MA, Medlock AE. Thoughts on interactions between PGRMC1 and diverse attested and potential hydrophobic ligands. J Steroid Biochem Mol Biol. 2017; doi: 10.1016/j.jsbmb.2016.12.020.

9. Wei JH, Yin X, Welander PV. Sterol Synthesis in Diverse Bacteria. Front Microbiol. 2016; 7:990.

10. Mayfield JA, Dehner CA, DuBois JL. Recent advances in bacterial heme protein biochemistry. Curr Opin Chem Biol. 2011; 15:260-266.

11. Hughes AL, Powell DW, Bard M, Eckstein J, Barbuch R, Link AJ, Espenshade PJ. Dap1/PGRMC1 binds and regulates cytochrome P450 enzymes. Cell Metab. 2007; 5:143-149.

12. Suchanek M, Radzikowska A, Thiele C. Photo-leucine and photo-methionine allow identification of proteinprotein interactions in living cells. Nat Methods. 2005; 2:261-267.

13. Cahill MA. Progesterone receptor membrane component 1: An integrative review. J Steroid Biochem Mol Biol. 2007; 105:16-36

14. Markov GV, Tavares R, Dauphin-Villemant C, Demeneix BA, Baker ME, Laudet V. Independent elaboration of steroid hormone signaling pathways in metazoans. Proc Natl Acad Sci U S A. 2009; 106:11913-11918.

15. Baker ME. Evolution of adrenal and sex steroid action in vertebrates: a ligand-based mechanism for complexity. BioEssays. 2003; 25:396-400.

16. Baker ME. Origin and diversification of steroids: Coevolution of enzymes and nuclear receptors. Mol Cell Endocrinol. 2011; 334:14-20.

17. Runko E, Kaprielian Z. Expression of Vema in the developing mouse spinal cord and optic chiasm. J Comp Neurol. 2002; 451:289-299.

18. Runko E, Kaprielian Z. Caenorhabditis elegans VEM1 , a novel membrane protein, regulates the guidance of ventral nerve cord-associated axons. J Neurosci. 2004; 24:9015-9026.

19. Runko E, Wideman C, Kaprielian Z. Cloning and expression of VEMA: a novel ventral midline antigen in the rat CNS. Mol Cell Neurosci. 1999; 14:428-443.

20. Neubauer H, Clare SE, Wozny W, Schwall GP, 
Poznanovic S, Stegmann W, Vogel U, Sotlar K, Wallwiener D, Kurek R, Fehm T, Cahill MA. Breast cancer proteomics reveals correlation between estrogen receptor status and differential phosphorylation of PGRMC1. Breast Cancer Res. 2008; 10:R85.

21. Cahill MA, Jazayeri JA, Kovacevic Z, Richardson DR. PGRMC1 regulation by phosphorylation: Potential new insights in controlling biological activity. Oncotarget. 2016; 7:50822-50827.

22. Hornbeck PV, Zhang B, Murray B, Kornhauser JM, Latham V, Skrzypek E. PhosphoSitePlus, 2014: mutations, PTMs and recalibrations. Nucleic Acids Res. 2015; 43:D512-520.

23. Sievers F, Wilm A, Dineen D, Gibson TJ, Karplus K, Li W, Lopez R, McWilliam H, Remmert M, Soding J, Thompson JD, Higgins DG. Fast, scalable generation of high-quality protein multiple sequence alignments using Clustal Omega. Mol Syst Biol. 2011; 7:539.

24. Ohta H, Kimura I, Konishi M, Itoh N. Neudesin as a unique secreted protein with multi-functional roles in neural functions, energy metabolism, and tumorigenesis. Front Mol Biosci. 2015; 2:24.

25. Kimura I, Konishi M, Miyake A, Fujimoto M, Itoh N. Neudesin, a secreted factor, promotes neural cell proliferation and neuronal differentiation in mouse neural precursor cells. J Neurosci Res. 2006; 83:14151424.

26. Kimura I, Nakayama Y, Konishi M, Terasawa K, Ohta M, Itoh N, Fujimoto M. Functions of MAPR (membraneassociated progesterone receptor) family members as heme/steroid-binding proteins. Curr Protein Pept Sci. 2012; 13:687-696.

27. Kimura I, Nakayama Y, Yamauchi H, Konishi M, Miyake A, Mori M, Ohta M, Itoh N, Fujimoto M. Neurotrophic activity of neudesin, a novel extracellular heme-binding protein, is dependent on the binding of heme to its cytochrome b5-like heme/steroid-binding domain. J Biol Chem. 2008; 283:4323-4331.

28. Kimura I, Konishi M, Asaki T, Furukawa N, Ukai K, Mori M, Hirasawa A, Tsujimoto G, Ohta M, Itoh N, Fujimoto M. Neudesin, an extracellular heme-binding protein, suppresses adipogenesis in 3T3-L1 cells via the MAPK cascade. Biochem Biophys Res Commun. 2009; 381:75-80.

29. Steentoft C, Vakhrushev SY, Joshi HJ, et al. Precision mapping of the human $\mathrm{O}-\mathrm{GalNAc}$ glycoproteome through SimpleCell technology. EMBO J. 2013; 32:1478-1488.

30. Ponten F, Jirstrom K, Uhlen M. The Human Protein Atlas--a tool for pathology. J Pathol. 2008; 216:387-393.

31. Ferrero E, Lo Buono N, Horenstein AL, Funaro A, Malavasi F. The ADP-ribosyl cyclases - the current evolutionary state of the ARCs. Front Biosci (Landmark Ed). 2014; 19:986-1002.

32. Kuramae EE, Robert V, Snel B, Boekhout T. Conflicting phylogenetic position of Schizosaccharomyces pombe. Genomics. 2006; 88:387-393.

33. Sipiczki M. Where does fission yeast sit on the tree of life? Genome Biol. 2000; 1:Reviews 1011.

34. Morrison DA. Phylogenetic tree-building. Int J Parasitol. 1996; 26:589-617.

35. McCallum ML, Pru CA, Niikura Y, Yee SP, Lydon JP, Peluso JJ, Pru JK. Conditional Ablation of Progesterone Receptor Membrane Component 1 Results in Subfertility in the Female and Development of Endometrial Cysts.
Endocrinology. 2016; 157:3309-3319.

36. Whitfield GK, Jurutka PW, Haussler CA, Haussler MR. Steroid hormone receptors: evolution, ligands, and molecular basis of biologic function. J Cell Biochem. 1999; Suppl 32-33:110-122.

37. Goldstone JV, Sundaramoorthy M, Zhao B, Waterman MR, Stegeman JJ, Lamb DC. Genetic and structural analyses of cytochrome P450 hydroxylases in sex hormone biosynthesis: Sequential origin and subsequent coevolution. Mol Phylogenet Evol. 2016; 94:676-687.

38. Bezzaouia A, Gallo A, Silvestre F, Tekaya S, Tosti E. Distribution pattern and activity of mitochondria during oocyte growth and maturation in the ascidian Styela plicata. Zygote. 2014; 22:462-469.

39. Mach RH, Zeng C, Hawkins WG. The sigma2 receptor: A novel protein for the imaging and treatment of cancer. J Med Chem. 2013; 56:7137-7160.

40. Jbilo O, Vidal H, Paul R, et al. Purification and characterization of the human SR 31747A-binding protein. A nuclear membrane protein related to yeast sterol isomerase. J Biol Chem. 1997; 272:27107-27115.

41. Hayashi T, Su TP. $\sigma-1$ receptors $\left(\sigma_{1}\right.$ binding sites) form raft-like microdomains and target lipid droplets on the endoplasmic reticulum: Roles in endoplasmic reticulum lipid compartmentalization and export. J Pharmacol Exp Ther. 2003; 306:718-725

42. Hayashi T. Sigma-1 receptor: the novel intracellular target of neuropsychotherapeutic drugs. J Pharmacol Sci. $2015 ; 127: 2-5$.

43. Hayashi T, Hayashi E, Fujimoto M, Sprong H, $\mathrm{Su}$ TP. The lifetime of UDP-galactose:ceramide galactosyltransferase is controlled by a distinct endoplasmic reticulum-associated degradation (ERAD) regulated by sigma-1 receptor chaperones. J Biol Chem. 2012; 287:43156-43169.

44. Hornick JR, Spitzer D, Goedegebuure P, Mach RH, Hawkins WG. Therapeutic targeting of pancreatic cancer utilizing sigma-2 ligands. Surgery. 2012; 152:S152-156.

45. Hertel C, Coulter SJ, Perkins JP. A comparison of catecholamine-induced internalization of betaadrenergic receptors and receptor-mediated endocytosis of epidermal growth factor in human astrocytoma cells. Inhibition by phenylarsine oxide. J Biol Chem. 1985; 260:12547-12553.

46. $\mathrm{Xu} \mathrm{J}$, Zeng $\mathrm{C}, \mathrm{Chu} \mathrm{W}$, et al. Identification of the PGRMC1 protein complex as the putative sigma-2 receptor binding site. Nat Commun. 2011; 2:380.

47. Haller JL, Panyutin I, Chaudhry A, Zeng C, Mach RH, Frank JA. Sigma-2 receptor as potential indicator of stem cell differentiation. Mol Imaging Biol. 2012; 14:325335 .

48. Hampton KK, Stewart R, Napier D, Claudio PP, Craven RJ. PGRMC1 elevation in multiple cancers and essential role in stem cell survival. Adv Lung Cancer (Irvine). 2015; 4:37-51.

49. Sun T, Wang Y, Wang Y, Xu J, Zhao X, Vangveravong S, Mach RH, Xia Y. Using SV119-gold nanocage conjugates to eradicate cancer stem cells through a combination of photothermal and chemo therapies. Adv Healthc Mater. 2014; 3:1283-1291.

50. Izzo $\mathrm{NJ}, \mathrm{Xu}$ J, Zeng $\mathrm{C}$, et al. Alzheimer's therapeutics targeting amyloid beta 1-42 oligomers II: Sigma-2/ PGRMC1 receptors mediate Abeta 42 oligomer binding and synaptotoxicity. PloS One. 2014; 9:e111899.

51. Peluso JJ, Lodde V, Liu X. Progesterone regulation 
of progesterone receptor membrane component 1 (PGRMC1) sumoylation and transcriptional activity in spontaneously immortalized granulosa cells. Endocrinology. 2012; 153:3929-3939.

52. Zhao Q, Xie Y, Zheng Y, Jiang S, Liu W, Mu W, Liu Z, Zhao Y, Xue Y, Ren J. GPS-SUMO: a tool for the prediction of sumoylation sites and SUMO-interaction motifs. Nucleic Acids Res. 2014; 42:W325-330.

53. Dores RM. Hagfish, Genome Duplications, and RFamide Neuropeptide Evolution. Endocrinology. 2011; 152:40104013.

(Received January 10, 2017; Revised February 21, 2017; Accepted February 22, 2017)

\section{Supplemental Data}

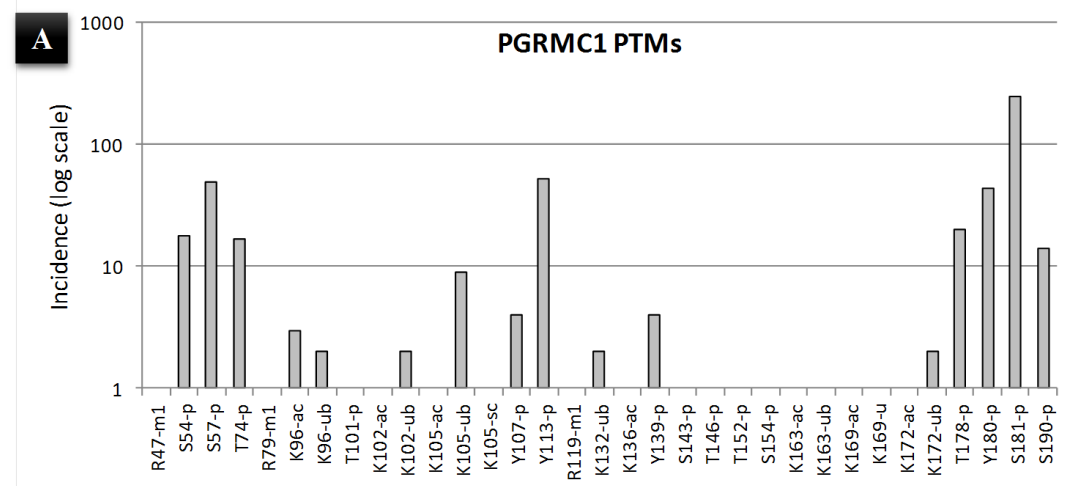

\begin{tabular}{|ll}
\hline Key: & \\
$\mathrm{p}$ & Phosphorylation \\
$\mathrm{ac}$ & Acetylation \\
$\mathrm{m} 1$ & Mono-methylation \\
$\mathrm{ub}$ & Ubiquitylation \\
ga & O-GalNAc \\
\hline
\end{tabular}
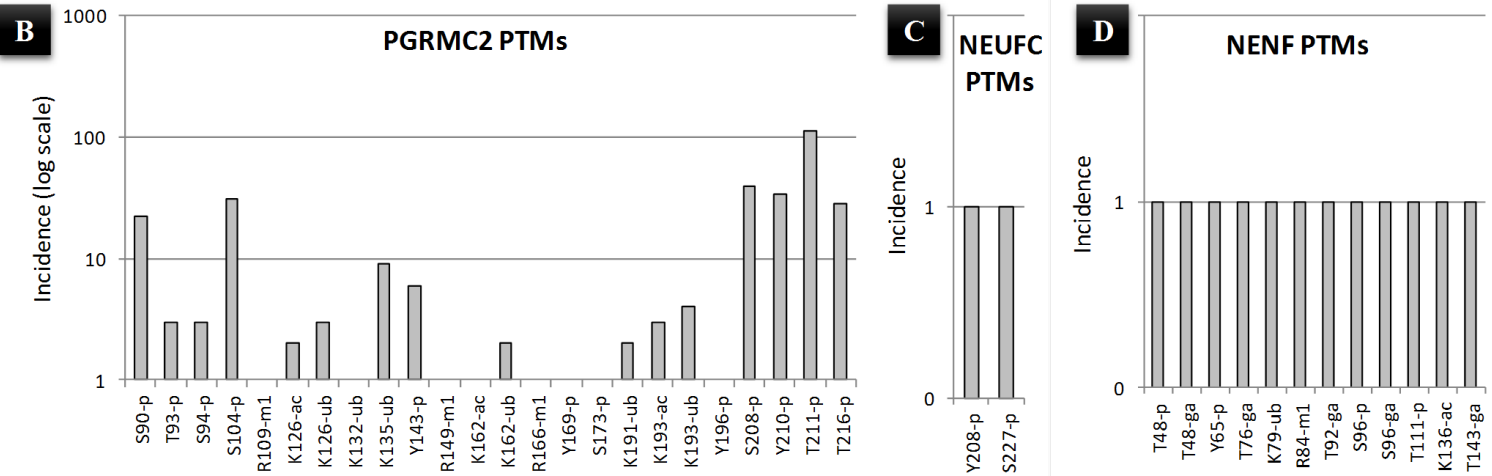

Figure S1. Post-translational modifications documented in the Phosphosite data base for human MAPR proteins PGRMC1 (A), PGRMC1 (B), Neuferricin (C) and Neudesin (D). 